\title{
MÁQUINAS DE COSTURA E MÁQUINAS DE ESCAPE: TRÊS NARRATIVAS DE FUGA E A CRIAÇÃO DE UM ESPAÇO-TEMPO BOLIVIANO EM SÃO PAULO
}

\author{
Rafael Simões Lasevitz ${ }^{1}$
}

Román e este senhor já conversavam há quase vinte minutos. Román dizia que precisava de tempo para poder passar suas idéias adiante, que era um processo lento e delicado, e que devia ser feito sem atropelos para evitar que os outros se chocassem com as coisas que dizia. O senhor reclamava-lhe de dores nas mãos, nos braços e nas costas. Fiz-lhe a pergunta já imaginando qual seria sua resposta.

- ¿Trabajas con costura?

- ¡Sí, con costura! Somos todos costureros aquí en este país, ¿verdad?

Não sei até que ponto este senhor me respondeu metaforicamente, até que ponto era de forma literal, e de qualquer forma, ambas as intenções eram válidas. O senhor havia se aproximado de mim e de Román enquanto nós dois conversávamos. Román era um xamã boliviano de origem quéchua, mas que preferia se apresentar como artista do que como xamã - dizia que era para evitar maiores manifestações desnecessárias de seu próprio ego. O senhor que viera até nós, viera em busca de Román como sua última esperança de tratamento após tentativas frustradas de tratar suas dores com a medicina tradicional e após ouvi-lo, Román pacientemente falara-lhe de seus métodos medicinais baseados essencialmente em usos ritualizados de chás e dos resultados que poderia obter através destes métodos. Mas sem querer se deter a este tópico, Román foi além, pois que também queria falar sobre outros temas, mais especificamente, da mentalidade do boliviano que vive em São Paulo - fosse este um boliviano genérico, fosse ele este boliviano que agora se colocava diante de nós.

- Pero, cuando uno está legalizado en este país, se abren las posibilidades. Porque hay mucha gente que trabaja en costura que tiene su profesión. Y ahora que está legalizado, hay que participar de la sociedad de este país. Porque aquí hay buenas posibilidades para todos.

- ¡Sí, claro!

- Si dices, "no, voy con mis paisanos, solo con mis paisanos”, ¡nadie progresa! ¡nadie progresa! Porque cuando uno se va de nuestro país, no es solo para buscar valor, ¡es para valorizar como persona también! Y este país te da esta posibilidad, ¡te dan mucha libertad social por aquí!

\footnotetext{
${ }^{1}$ Université de Montréal, Canadá.
} 


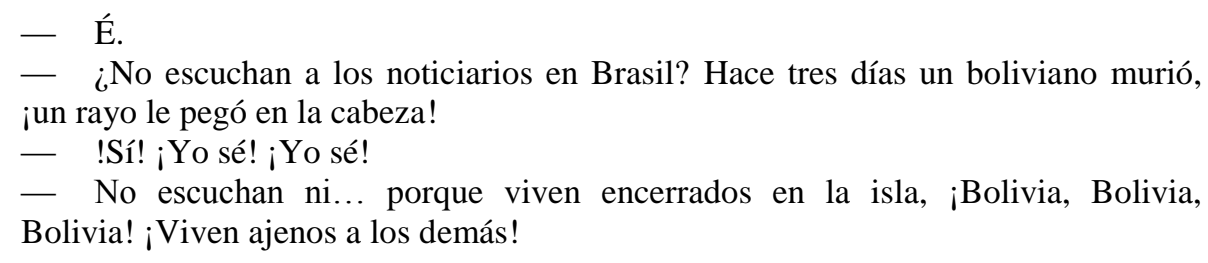

Enquanto ouvia a conversa, me pus a observar este senhor. Era baixo, de pele morena e cabelos curtos, como a maior parte dos milhares de bolivianos que freqüentam a Feira Kantuta todos os domingos no bairro do Bom Retiro. Falava pouco, sempre respondendo com frases curtas às indagações de Román. Tinha um aspecto que me passava a impressão de um certo constrangimento por estar ali, conversando com aquele senhor alto que se lhe apresentara como xamã, ainda que me chamasse a atenção o fato de respondê-lo muitas vezes em um tom defensivo, de voz alta, como se precisasse defender-se de alguma acusação que Román lhe fazia. Román havia me dito que muito raramente recebia bolivianos em sua barraca na Kantuta, ainda que a feira fosse muito mais frequientada por eles do que por brasileiros. Era o último domingo antes do domingo de carnaval boliviano e já começavam a desfilar pela praça da Kantuta alguns pequenos grupos que faziam uma espécie de desfile pré-carnavalesco e muitos que antes perambulavam entre as várias barracas de comida e bugigangas que se espalhavam pela feira, agora se aglomeravam em torno dos grupos de dança.

\section{II}

Román já me dizia um pouco destas coisas antes da chegada deste senhor. Reclamava-me dos bolivianos que vinham ao Brasil, esta terra de "mucha libertad social", somente para se fecharem em si próprios, em suas oficinas de costura onde trabalhavam muitas vezes de madrugada a madrugada, em suas próprias feiras na Praça Kantuta, em suas próprias ruas na Rua Coimbra, em suas próprias idéias, e claro, sua própria cultura. Mas então que começo este ensaio tentando fazer de Román, um artistaxamã boliviano de origem quéchua e que vive há quinze anos no Brasil, essa espécie de interlocutor entre mim e a comunidade boliviana que vive em São Paulo. "Somos todos costureros aquí en este país, ¿verdad?”, dizia o senhor que conversava conosco na Kantuta. Mas Román não era costureiro, e nunca havia sido costureiro. Porque então falar de Román? 
III

Escrevo este artigo tomando por base minha pesquisa de campo feita ainda para o mestrado $^{2}$, sempre na cidade de São Paulo. Falo cidade de São Paulo por ser mais difícil em princípio localizar minha pesquisa em um espaço mais restrito, especialmente enquanto ainda a tomo por "pesquisa com a comunidade boliviana de São Paulo", como costumo responder aos que me perguntam. O problema é que não há muito claramente um espaço análogo a esta comunidade e os bolivianos da cidade, cuja grande maioria chega para trabalhar em oficinas de costura, invariavelmente aceitam a proposta de também viver no local de trabalho, oficinas administradas por brasileiros, coreanos, judeus, paraguaios, peruanos, e até mesmo bolivianos, e que se espalham de forma mais ou menos arbitrária pela cidade, ainda que com notável concentração um tanto maior em alguns bairros mais centrais da cidade, como o Bom Retiro, o Brás, o Pari e a Mooca.

Por outro lado, essa peculiaridade espacial da imigração boliviana em São Paulo é justamente o que me faz tomar minha pesquisa de outra forma, a comunidade boliviana de São Paulo está demasiado espalhada e a essa altura, já é demasiadamente grande para estar ao meu alcance, de modo que então minha pesquisa passa a tratar mais especificamente de espaços de circulação boliviana nestes bairros mais centrais e, mais precisamente ainda, nos dois principais espaços essencialmente bolivianos da cidade, ou seja, a Praça da Kantuta, no Bom Retiro - ainda que se trate de uma praça que possa ser assim tratada somente aos domingos, quando a feira boliviana local atrai as suas multidões - e a Rua Coimbra, na Mooca, essa sim, sempre bastante boliviana, tomada por restaurantes de comida típica e salones de peluquería e, até aonde pude acompanhar, única rua paulistana tão claramente caracterizada pelo comércio andino.

IV

Após deixar o metrô na Bresser, eu seguia pela própria Rua Bresser por alguns quarteirões ainda antes que a Bresser cruzasse com a Coimbra. Nunca me preocupei muito em contar quantos quarteirões eram já que podia avistar à distância as sombrinhas que protegiam um ou dois comerciantes bolivianos que deixavam seus carrinhos e barracas de comida já ali na esquina. Era curioso que a área boliviana da Kantuta era

\footnotetext{
${ }^{2}$ Realizado entre 2009 e 2011 no departamento de antropologia da Universidade de Brasília.
} 
estritamente delimitada pelos limites da rua. A seqüência infindável de barracas especialmente nos sábados, quando havia a feira da Coimbra, que tomava a rua quase que por completo - se encerrava rigorosamente nos limites das esquinas da rua, fosse para frente ou para trás. Quase na esquina, mas já na Coimbra, era também onde ficava o salão de cabeleireiros do Chalo. Na entrada, uma larga fachada, que anunciava não somente o salão, mas também um negócio secundário de ponto de venda de passagens para uma companhia de ônibus que fazia o trajeto Brasil-Bolívia - ironicamente, como na Coimbra, também tomando o devido cuidado de não ultrapassar os limites devidos da fronteira brasileira. A fachada por sua vez, contrastava com a pequena e apertada entrada que dava para uma escadaria, em geral, abarrotada de pessoas que, logo se notava, não eram exatamente clientes esperando por um corte de cabelo. Estavam ali atentas, esmiuçando o painel repleto de anúncios de empregos que o salão publicava. Anunciavam empregos para costureros, overloquistas, rectistas e cocineras $^{3}$ - e nada além disso, posto que os papéis padronizados de anúncio, à base de marcação de xis, não deixavam nenhum espaço para outras opções de emprego. A venda de espaços para anúncios em painéis era uma estratégia bastante comum de comerciantes bolivianos para acrescentar alguma renda e algum público a mais em seus estabelecimentos, especialmente na Rua Coimbra, depois que a regularização da Feira da Kantuta junto à prefeitura aumentou a fiscalização contra o que era taxado de "recrutamento de mão-deobra escrava" por agentes do Estado, o que chegou inclusive a levar alguns feirantes da Kantuta a mudarem seus negócios para regiões que contassem com menor presença da fiscalização estatal, como era o caso da própria Coimbra.

Quando me sentei para conversar com Chalo era já quase fim de tarde de uma terça-feira e o movimento era fraco, o que tornava muito mais fácil qualquer conversa com qualquer comerciante da rua. Não havia nenhum cliente sendo atendido, e além dele e dois funcionários, havia no salão somente sua filha pequena que assistia compenetrada a desenhos animados na televisão. Chalo, boliviano de La Paz, havia chegado em São Paulo em 1998, e, no dia desta conversa que segue abaixo, contava 37 anos de idade.

\footnotetext{
${ }^{3}$ Em português, respectivamente: costureiros, overloquistas, retistas e cozinheiras. A overloque é uma máquina de costura semi-industrial ou industrial que costura, chuleia e corta o excedente do tecido ao mesmo tempo. Já o retista trabalha com máquina de costura reta, mais popular que a de overloque e que, como o próprio nome já indica, costura somente de forma reta.
} 
Bueno, yo aquí he venido sólo. He venido hace... tenía un primo aquí y mi primo me dio cualesquier por venir y... entonces, ¿que tenía que hacer yo? Ver lo que los otros bolivianos han hecho. ¿Cómo? Ir hasta la [Policía] Federal, les presenté mi documento. Fue más o menos hace diez años atrás. Aí llegué aquí [en São Paulo], no sabía a quién ubicar, aí conocí uno, conocí otro, y entonces yo comencé a trabajar en costura. Y no había más caso. Entonces el trabajo de costura es muy pesado. Empiezas a las siete de la mañana, se descansa media noche. Con descansos de media hora en el almuerzo y en la hora del té, o en el café, como se llama. Entonces, yo no quería continuar siempre a trabajar con costura, quería trabajar con otra cosa. Porque todos mis conterráneos, mis paisanos o, como se llama... parientes, ellos... hallan que la costura es ¡muy, muy, muy pesada! Se trabaja mucho, se gana poco. Entonces mi idea era siempre de salir de la costura. Porque todos los bolivianos que veniran aquí, ellos no son costureros. Ellos tienen otro oficio, digamos, poden ${ }^{4}$ ser carpintero, sapatero, chofer, y demás, de otras cosas. Entonces, yo trabajé en costura, trabajé con boliviano, trabajé con coreano. No que me trataran mal, me trataran... regular. Porque yo también cumplia con todo. Se iba a portarme mal, entonces ellos también iban a portarse mal conmigo. Se escuchan de malos tratos. Es verdad, algunos. No todos. Pero yo he tenido la oportunidad de trabajar, ha sido de que ellos gustaran de mi trabajo, ellos también han correspondido, conmigo... En el época yo no sabía si lo que ellos me pagaban estaba bien, en el nivel del trabajo. Tal vez ellos estaban me pagando poco y yo pensando que estaban me pagando consciente. Pero, yo salí. Fui a... ¿cómo se llama? En el primero mes no conseguí, el segundo mes comencé a salir una cuadra, el tercero mes, conseguí salir, dar una volta en la segunda cuadra, el cuarto mes y así sucesivamente, avanzando más, aquí y allá. He ido a, como se llama, a Ipiranga, donde hay una escuela de cabeleireiro, de peluquería. Entré ahí, curiosé, entonces no sabía entender el idioma, fui más allá, conseguí allí ir al Senac, en Liberdade, en el barrio de Liberdade. Y comencé a pasar en unos cursos ahí. Aí, trabajaba en costura en los días, los sábados. Entonces, ¿que hacía yo? Después de los horarios normales, trabajaba una hora más. ¿Para qué? Para salir el día de sábado, y estudiar, cosa que el dueño no quería. Entonces yo le rogué bastante para que el me aceptase a trabajar una hora más en los cinco días, de lunes a viernes. (...) Y entonces por fin, salí de la oficina para ir a trabajar con un brasilero, para trabajar como peluquero. Y pasé mucha vergüenza allá, por causa del idioma. Aí trabajé un tiempo con él, aí me fui para el otro lado, encontré con una peluquería boliviana. Aí comencé a trabajar, unos tres años así, trabajando todos los días, de lunes a domingo. Trabajé, luego me vin aquí a trabajar en el 2002, año del mundial. Y desde esta época estoy aquí, en la Coimbra.

É interessante pensar a idéia de máquina de guerra nômade deleuziana (1997) dentro de um contexto de imigração. A máquina de guerra se caracteriza por ser uma espécie de vetor de oposição ao sempre-englobante, interiorizante aparelho de Estado. Pois temos aqui para nos ajudar a pensar uma narrativa de um processo de migração de um boliviano de La Paz para São Paulo. Se pensar a migração como um movimento que

\footnotetext{
${ }^{4}$ Chalo, como outros bolivianos com quem conversei, frequentemente misturavam português e castelhano durante nossas conversas, ainda que eu me esforçasse por conversar com eles em castelhano. Tentei preservar esta mistura nas citações ao longo deste ensaio.
} 
se dá por um alisamento do espaço é inevitável, reconfigurando redes de interação até então firmemente estabelecidas ao mesmo tempo em que esta reconfiguração se dá também em relação a configurações econômicas e políticas bolivianas, por outro lado a entrada no Brasil passa também necessariamente por uma notável dinâmica, ao mesmo tempo traumática e estratégica, de um novo estriamento do espaço. Chalo partiu em busca de melhores condições econômicas de vida e, em última instância, de ascensão social. A ruptura com a Bolívia (Estado, política, economia) se deu desde o princípio a partir de uma continuidade da própria Bolívia (família, primo), necessário no Brasil como que para evitar maiores deslizamentos perante o alisamento dramático da imigração. O primo, contudo, não era suficiente, e a falta de referências que guiassem Chalo em uma São Paulo completamente desmapeada acabou por levá-lo a buscar instrumentos que viabilizassem sua existência na cidade. Chalo tinha que fazer aquilo que os outros bolivianos haviam feito. Haviam afinal pegadas a serem seguidas, e sua narrativa faz questão de enfatizar esse momento de comunhão de trajetórias, como se esse reencontro com a Bolívia (rede, língua, caminhos, memória) devesse ser reencenado até hoje na forma de narrativa biográfica contra o esquecimento, talvez contra o borramento dessas pegadas, talvez ainda temendo que a Bolívia (rede, língua, caminhos, memória) possa um dia novamente não mais estar ali, diante de si.

Curiosamente, seguir o passo dos bolivianos o leva imediatamente ao encontro do Brasil (Estado), onde se faz ser reconhecido, apresenta seus documentos, se deixa localizar novamente após a fuga inicial, deixando-se reter um pouco mais pelos mecanismos englobantes do aparelho do Estado do qual acabara de se soltar. Não tarda, Chalo enfim encontra a rota boliviana mais típica entre as rotas bolivianas possíveis em São Paulo, ou seja, a do trabalho com costura. É curiosa essa coincidência de trajetórias que vai marcar a maior parte das conversas que tive durante minha pesquisa na cidade. A costura como caminho necessário para este projeto de migração pode aparecer de diversas formas na vida de um boliviano. Há muita demanda por mão-de-obra barata nesta área em São Paulo, e em geral o boliviano de origem aimara e quéchua das redondezas de La Paz tem ao menos algum nível de prática com este tipo de atividade. Muitos acabam descobrindo essa possibilidade de trabalho com costura no Brasil através de anúncios nas ruas de La Paz. Outros, através de amigos que viram anúncios nas ruas de La Paz. Outros simplesmente já têm parentes que vivem no Brasil e decidem juntar-se a eles por razões diversas. Na falta de outras referências, Chalo e muitos outros 
seguem o caminho da costura como um caminho inevitável, nem que seja somente como uma salvaguarda, enquanto outras rotas não se manifestam.

E não era fácil fazê-las se manifestarem. Caminhar por São Paulo para Chalo era muito difícil, e São Paulo permaneceu desmapeada ainda por um mês antes que conseguisse começar a "salir una cuadra". Ora, Chalo havia acabado de tomar a decisão de descer os Andes e migrar de um país a outro mas depois de chegar em São Paulo, levou meses e meses para conseguir sair do próprio bairro em que morava. Quando foi que percorrer uma única quadra tornou-se tão difícil? Deleuze e Guattari em seus Mil Platôs (1997) defendem a idéia de que assim como a máquina de guerra coexiste em disjunção inclusiva com o aparelho de Estado, assim também o liso se compõe com o estriado e o estriado não está jamais desprovido do próprio liso. Chalo, porém, me faz tentar fazer este exercício de forma um pouco diferente. Não é somente que o alisamento do espaço necessário para que se realize o choque da migração esteja sempre em tensão com seus próprios estriamentos internos, mas também que - e aqui não tanto tento modificar a essência dessa idéia e muito mais brincar com suas ênfases - a partir do momento em que se toma a decisão de deslocamento, este deslocamento passa a se caracterizar essencialmente por uma série de estratégias de recuperação da Bolívia e do referencial boliviano que lhe indica os passos a serem tomados. A trajetória da costura, como diz o próprio Chalo, é "muy, muy, muy pesada". Pode-se discutir quais seriam as opções de trabalho de um boliviano com formação básica que vem viver em São Paulo e talvez se possa deixar convencer de que não há muito a ser feito além das fronteiras da costura. Por outro lado, não me parece que o parâmetro central para que Chalo, como outros bolivianos, tome a decisão de seguir por esta trajetória seja tanto o de uma análise ampla destas opções como o de uma confiança quase que irrestrita, ao menos inicial, na própria repetição de trajetórias bolivianas através do caminho já bem mapeado da costura que, afinal, oferece ao recém-chegado o conforto análogo ao de velhas tradições culturais.

Em última instância, dentro do projeto libertário da imigração, o que parece se encontrar é um vasto conjunto de estratégias de auto-contenção deste projeto libertário. Alegoricamente, as oficinas de costura fecham o imigrante em quatro paredes de segunda a sábado, são espaço de trabalho e de moradia ao mesmo tempo, e dessas quatro paredes, de fato, quase não se sai. Chalo não conseguiu sair de sua quadra no primeiro mês porque as paredes - paredes espaciais e também temporais - de sua 
oficina de costura não ajudavam, mas talvez também por não ter conhecimento de pegadas bolivianas (a trajetória boliviana é a trajetória classificada como possível) que lhe dessem segurança para que realizasse essa espécie de segunda ruptura, ainda que tão curta que pudesse ser caminhada à pé. Chalo é um dos poucos bolivianos que conheci que se arriscaram a essa segunda migração ou fuga, essa nova ruptura, não somente de sair para conhecer uma quadra, e depois outra, e outra, mas sim, de buscar alternativas de trabalho. De quadra em quadra, chega, também alegoricamente, ao bairro da Liberdade, onde dá início a uma considerável mudança de trajetória rumo aos salões de cabeleireiros da cidade.

\section{VII}

Entre a Rua Três Rios e a Rua da Graça, no Bom Retiro, nota-se uma concentração crescente de lojas de vendas de fios e equipamentos para a costura. Nos arredores da Graça, isso chega a tal ponto que já nem se notam mais os restaurantes coreanos, gregos e brasileiros tão presentes nas quadras anteriores. Aliás, no cruzamento da Graça com a Júlio Conceição, onde marquei de me encontrar com o Léo, um amigo paraguaio que iria me apresentar a seus ex-patrões bolivianos, Gonzalo e Marta, a vista se perdia sem ser capaz de avistar sequer uma lanchonete, e tive de passar o ligeiro contratempo de passar um pouco de fome enquanto esperava. Léo chegou por volta das seis horas daquela tarde de quinta-feira, logo após o término do seu expediente em outra oficina em que agora trabalhava. Partimos dali e rapidamente chegamos ao prédio onde trabalhavam o casal de bolivianos, além de outros peruanos e paraguaios que naquela hora, também terminavam seus expedientes e partiam - ao contrário de muitas oficinas, naquela, os empregados viviam em suas próprias casas e não no próprio ambiente de trabalho. Léo gritou do térreo chamando por seu Gonzalo que logo apareceu à janela e em seguida, desceu para nos encontrar. Fiquei frustrado naquela tarde, imaginava que teria enfim a oportunidade de conhecer uma oficina de costura boliviana por dentro. Ao longo de toda a nossa conversa, porém, seu Gonzalo não fez nenhuma menção de convidar a mim ou ao Léo para subir. Não sei se para preservar a oficina ou para preservar a própria casa, habitualmente um lugar bastante restrito a estranhos pelos bolivianos que pude conhecer. Gonzalo tinha pouco mais de quarenta anos, aparência bonachona com fortes traços indígenas, como Chalo também tinha. 
- Estoy en Brasil hace doce años. Siempre trabajando con costura. Antes en otras oficinas pero en esta oficina de ahora, creo que hace más o menos... seis años. Vivo aquí con mi esposa y tres hijas. Tengo también un hermano aquí, un hermano que trabaja con costura aquí, cerca de aquí.

- Y ello juega al fútbol también, ¿o no?

Fiz a pergunta a Gonzalo em tom de descontração. Logo antes de chegarmos, Léo me advertira que eu não fizesse perguntas sobre a oficina de costura logo de início, e que pensava que seria melhor se eu demonstrasse interesse em sua equipe de futebol. Existem centenas de equipes bolivianas de futebol amador em São Paulo. De acordo com Léo, grande parte delas corresponde a oficinas de costura, tendo seus funcionários - os que querem jogar, claro - como jogadores. Gonzalo me respondeu rindo.

- No, ello no juega al fútbol. Prefiere bailar. Tiene un grupo de folclore de que participa, para bailar a... cumbia, chicha... Soy el tercero hermano más viejo, mientras que él es el sexto.

- ¿Y los otros hermanos, no han venido?

- Los otros no, los otros no les quiseron venir. Se quedaron en Bolívia, en La Paz todos ellos. Son nueve hermanos allá. Pero yo sí, me gusta muchísimo al fútbol, tengo mi propia equipa de fútbol, jugamos todos los sábados en una cancha, en, en, cerca de Praça Princesa Isabel. Se llama Tres Fronteras la equipa, el time. Se llama así porque cuando creamos el time, en 2006, teníamos en la oficina costureros de Bolivia, de Peru y de Paraguay. ¡Hasta hoy los tenemos! Y como el time era el time de la oficina, y tenía también jugadores de los tres países, se quedó entonces Tres Fronteras.

- ¿Y te gusta hacer otras cosas también, te gusta bailar, salir para hacer otras cosas...?

- ¿Yo? No, no... solamente el fútbol. Mira... a algunos, les gustan el fútbol, a otros les gustan bailar - diz bailar enquanto leva o dedo polegar à boca, dizenddo 'bailar' como quem quer dizer 'beber'. Léo e Darío, um costureiro paraguaio que trabalhava para Gonzalo e que agora ouvia nossa conversa, riem na mesma hora ¡a mí me gusta el fútbol! completa Gonzalo.

- Pero, me ha dicho que vive en Brasil hace doce años, ¿verdad? ¿Pero vuelves a Bolivia con frecuencia, como es eso?

- ¡Sí, sí, vuelvo siempre a Bolivia, para ver a la familia, los amigos! Vuelvo siempre a la Bolivia, a cada dos o tres años, ¡siempre!

Gonzalo fala em tom sério, mas Léo e Darío riem novamente. Dois ou três anos era bastante tempo, em geral se volta a cada seis meses ou, no máximo, um ano. Após mais alguns minutos de conversa, Gonzalo chama por sua esposa Marta no interfone do prédio, pedindo que nos trouxesse algumas folhas de coca para animar a conversa. Pouco depois, Marta desce, trazendo na mão um saco de folhas que Gonzalo oferece a todos nós. Marta era um pouco mais nova do que Gonzalo, mas bastante parecida em 
estatura, e com um sorriso aberto, sempre na mesma medida, nunca mais largo ou mais estreito. Como ficara conosco, aproveitei para trazê-la também para a conversa, perguntando-lhe um pouco sobre a sua própria versão da vinda de sua família para o Brasil:

\footnotetext{
- Estoy casada con Gonzalo ya hace... dieciséis años. Pero él ha venido para cá antes que yo. Se quedó aquí por dos años antes que yo, después de dos años es que yo me fui. Fue difícil este tiempo de separación, verdad, pero tenía que ser, yo tenía que esperar pues que no había dinero para venir. Tenía que esperar para ganar el dinero (...). Pero me gusta mucho aquí en São Paulo. Sí, porque aquí... aquí en São Paulo hay mucho más posibilidades de trabajo. En Bolivia yo trabajaba como vendedora de hot dog, a la noche, trabajaba casi todas las noches así. Cualquier trabajo que uno tiene, hay que pegar el ómnibus, perder tiempo, tal y cual, para ir para trabajar. Es así para todos, porque todos viven muy, muy lejos del trabajo, no hay como vivir cerca del trabajo.

- Pero, ¿cuánto tiempo se perdía en el ómnibus para ir hasta el trabajo?

- ¿Cuánto tiempo de ómnibus? ¡Unos veinte, treinta minutos! ¡Pero aquí no! Porque aquí hay la comodidad de poderse trabajar en su propia casa. Entonces que aquí, yo trabajo un poco, voy hasta el frigorífico, se toma un, un yogur, se vuelve, escucha el radio, a la tele, se vuelve a trabajar. Es muy mejor así, se tiene todo a su propio alcance a todo tiempo. Y se tiene la familia junto a ti todo el tiempo, para charlar, para estar con los hijos.

- Pero se trabaja muy más, ¿verdad?

- Verdad, se trabaja más, pero... pero vale la pena por toda la comodidad.
}

Após mais algum tempo conversando, me despeço de Gonzalo e de Marta com a promessa de poder jogar de goleiro pelo Tres Fronteras no próximo sábado. Era fim de expediente, e estavam cansados. Ainda que muitas vezes trabalhassem além do expediente - afinal, tinham a "comodidade" de ter o trabalho a fácil acesso -, naquela noite já não trabalhariam mais. Antes de me despedir, perguntei a Gonzalo se poderíamos conversar melhor em outra hora. Respondeu-me que sim, que de repente, durante o trabalho seria melhor. Perguntei-lhe então se não haveria algum problema, se eu não iria atrapalhar a costura. Gonzalo sorriu.

- ¡No, no, seguro que no! Mira, Rafael, ¡la mano costura, pero es la boca quien habla!

\section{IX}

Após as primeiras fugas, vem outras. Mais do que outros trabalhos, a costura frequentemente enraíza o corpo - e provavelmente também a mente - a extremos. Em outros termos, trata-se de uma situação de territorialização dramática, e que territorializa 
dramaticamente o próprio tempo, que passa a se caracterizar fundamentalmente enquanto tempo do trabalho e para o trabalho. A imigração parece libertar o espaço, mas prender o tempo. A segunda fuga, no caso, é talvez nem tanto uma fuga espacial como parece ser a primeira - espacial em termos, pois podemos considerá-la mais econômica do que espacial - e muito mais uma fuga temporal.

É interessante pensar-se assim, pois que, seguindo-se este raciocínio, compreendese melhor uma questão que é posta por alguns autores que pensam a questão da imigração boliviana em São Paulo (especialmente Cymbalista e Xavier, 2007), ou seja, a questão da organização territorial do boliviano no espaço urbano da capital paulista. De acordo com Cymbalista e Xavier (2007), os padrões territoriais bolivianos na cidade não parecem seguir os padrões de nenhuma outra comunidade conhecida de migrantes. Ao contrário, por exemplo, do que ocorre com italianos, árabes, japoneses e judeus, não há um bairro tipicamente boliviano na cidade, nem sob a forma de gueto (Wacquant, 1996, Crush, 2005), nem de enclave étnico (Qadeer, 2004, Marcuse, 2004). Não há, enfim, um claro e definido 'lá' boliviano em São Paulo (Cymbalista e Xavier, 2007: 10) - a Rua Coimbra parece aos poucos configurar este 'lá' boliviano, ainda que se trate de aglomeração bastante recente de comércio e que ocupa pouco mais que um quarteirão no bairro da Mooca. O ponto que quero propor aqui é o de pensar essa territorialização do boliviano em São Paulo menos como uma territorialização espacial, que agrupa tradicionalmente essas noções de bairro, gueto, enclave, entre outras, e mais como uma territorialização temporal, e mais uma vez retomo a idéia de uma libertação do espaço em oposição a uma prisão do tempo, este sim, enraizante e conformador de trajetórias coesas e que servem de referências umas as outras, umas seguindo os passos das outras. Digo isso no sentido de que a maior parte dos bolivianos que chegam em São Paulo hoje em dia não tem por referência tanto um espaço referencial para onde ir quanto tem uma oficina de costura, em qualquer lugar da cidade, boliviana ou não, mas que, já sabem, lá poderão trabalhar e viver. Separados no espaço, mas unidos pelo tempo do trabalho, esta relação parece inverter-se de forma notável da hora do almoço dos sábados até a noite dos domingos. É o momento em que o tempo afinal é libertado para transformar-se em espaço, e milhares de bolivianos se deslocam rumo à Feira da Coimbra (aos sábados) e à Feira da Kantuta (sempre aos domingos).

Gonzalo e Marta, ao contrário, preferem partir para outro espaço, o espaço criado pelas tardes de futebol em uma quadra do corpo de bombeiros em frente à Praça 
Princesa Isabel, no centro de São Paulo. Lá jogam tanto homens quanto mulheres, inclusive duas filhas de Gonzalo e de Marta, que fazem parte da equipe feminina de futebol do Tres Fronteras. Em geral, quando pergunto a bolivianos da cidade suas linhas de fuga possíveis em relação ao tempo do trabalho, à exceção de passeios familiares pelas duas principais feiras bolivianas da cidade - há ainda uma terceira, bem menor, na Rua Anhaia, no Bom Retiro - me respondem invariavelmente através da tríade de escape do futebol, dos bailes e da bebida. Gonzalo, no caso, ainda sintetizou a tríade em dicotomia através de seu gesto com o dedo polegar quando falava do bailar. De fato, é bastante comum escutar-se em São Paulo bolivianos reclamando de paisanos que consumiriam bebidas alcoólicas em demasia. Se por um lado as reclamações são freqüentes, chegando a haver até mesmo campanhas em editoriais de pequenos jornais da comunidade boliviana local contra o consumo excessivo de álcool, por outro lado, também é comum que se reconheça a bebida como uma das principais vias de fuga do tempo do trabalho e, certamente, das mais intensas.

Esta oposição entre o trabalho e o não-trabalho, ou trabalho e lazer e seus tempos e seus espaços, deve ser visto aqui não como oposição absoluta, mas como uma oposição repleta de interpenetrações. Ou em outros termos, não se pode acreditar de todo no caráter totalizante do tempo do trabalho durante o próprio tempo do trabalho. Léo, que trabalhara por algum tempo na oficina de Gonzalo, me contou um pouco sobre as possibilidades de fuga dentro do próprio ambiente de trabalho. Nas oficinas em geral, especialmente nas bolivianas, invariavelmente há um rádio ligado em uma estação boliviana - transmissão, aliás, quase sempre clandestina, como chegaram a me confessar até mesmo alguns radialistas da comunidade. A pauta das rádios é sempre mais ou menos a mesma, intercalando músicas bolivianas e peruanas com informes para a comunidade a respeito de eventos sociais, questões de documentação, e notícias da imprensa andina. De acordo com Léo, a sociabilidade entre os costureiros das oficinas era bastante facilitada com a rádio, que acabava funcionando com uma espécie de pequena fábrica de assuntos, servindo de via de fuga para um complexo corporal quase que absolutamente territorializado pelas máquinas retas, overloques, paredes, teto e rolos de fios e tecido bastante lacônicos por si sós - ruidosamente lacônicos, diga-se de passagem. E claro, como disse Gonzalo e nunca é demais lembrar: por mais engessado que esteja o corpo, "es la boca quien habla". 
Marta também enfatiza a importância para ela desta interpenetração entre esferas, o trabalho, a casa, a família, a geladeira, a televisão. Ao mesmo tempo em que as possibilidades de movimento se restringem às fronteiras do apartamento (espaço) de forma bastante rigorosa, Marta não faz observações significativas em relação a essas fronteiras como o faz em relação às fronteiras do trabalho (tempo) e suas respectivas linhas de escape que, por sua vez, não escapam às fronteiras do apartamento (espaço).

Por outro lado, nota-se que o discurso de Marta vai além. Marta conta que queria vir ao Brasil desde o princípio, e ainda que a despedida seja sempre bastante difícil e chorada, teria vindo assim que pôde, pois seu marido já tinha vindo, e haviam as dificuldades econômicas na Bolívia - que durante a década de 90, passou por crises econômicas bastante severas. O curioso é que Marta enfatiza especialmente um aspecto específico para caracterizar esse seu movimento migratório em particular. Vivia longe do trabalho, o que lhe forçava a deslocar-se de casa para o trabalho e do trabalho para casa com bastante frequiência. Na narrativa de Marta, foi este em última instância o incômodo que mais mereceu relevo, o incômodo do deslocamento - ainda que uma hora diária no trânsito para qualquer paulistano, há que ser dito, dificilmente seria vista como incômoda. Marta parece querer nos mostrar aqui uma espécie de quarto tipo de fuga, uma fuga migratória da própria fuga, esta cotidianizada nas idas e vindas constantes dos ônibus entre o centro e a periferia da Grande La Paz. Foge, enfim, do movimento territorializado do trabalho na Bolívia, o faz através de um movimento de nomadismo dramático que é sempre o movimento da migração, e novamente, chegando ao Brasil, se equipando de todas as estrias possíveis para conter seu próprio excesso de movimento. No Brasil, o trabalho em oficinas de costura, primeiro na oficina de outros e depois, em sua própria, já não parece mais como parecia antes estar libertando o espaço e prendendo o tempo. Marta inverte essa relação em seu discurso. Prende o espaço para libertar o tempo, sob a forma de rádios, televisores, geladeiras, família, bate-papos, intercalados sempre, claro, com o trabalho. Múltiplas fugas, presas em um mesmo espaço. 
São três as fugas que dão título a este ensaio. São as fugas de Chalo, Gonzalo e Marta, como poderiam ser também as de tantos outros bolivianos - e paraguaios - com quem tive contato durante minhas pesquisas de campo em São Paulo. São também três tipos diferentes de fuga que destaco ao longo deste ensaio, mas poderiam ser quatro ou cinco, se eu tivesse seguido meu planejamento inicial para as páginas que se passaram. De qualquer forma, creio ter utilizado estas fugas mais como alegorias para pensar dinâmicas de movimentos e contenções de movimentos em um cenário de migração andina do que como qualquer outra coisa, e justifico minhas escolhas neste ensaio neste sentido, não pretendendo esgotar as possibilidades de análise aqui contidas. Assim, enquanto alegorias, temos uma primeira fuga no que seria a fuga de uma primeira Bolívia, não tanto a social, não tanto a cultural, não tanto o referencial dos caminhos que se repetem, mas de uma Bolívia econômica, fuga esta narrada no princípio de quase todas as narrativas de partidas bolivianas para São Paulo da década de 90 até os dias de hoje. A segunda fuga por sua vez ficou bastante marcada na narrativa de Chalo, aí sim, uma fuga das já mapeadas rotas bolivianas rumo ao trabalho nas precárias oficinas de costura da cidade, e que era uma fuga de dentro da oficina para fora, para o quarteirão que contornava esta oficina, e depois para o próximo, e para o outro, sempre lentamente, um passo por vez. Enfim, há a terceira fuga marcada pela narrativa de Gonzalo, uma fuga que também partia dos interiores das oficinas de costura, porém sem perder os passos bolivianos como referência, sem perder de vista as talvez necessárias estrias do espaço que a comunidade boliviana oferecia. A terceira fuga, para tentar sintetizá-la, era a fuga do tempo do trabalho rumo ao espaço do lazer, ainda que ambos pudessem - e tivessem que - se confundir e se interpenetrar com facilidade.

Neste trabalho de comparação de narrativas de movimentos, é interessante perceber a forma como os movimentos iniciais de fuga e seus primeiros momentos tendem a coincidir muito mais entre si do que todos os outros e as trajetórias iniciais pelas oficinas de costura de São Paulo acabam se repetindo quase que inevitavelmente. Os bairros étnicos são em geral a primeira grande referência do imigrante no processo de contenção da liberdade exacerbada pela própria dinâmica da migração, que destrói os mapas que orientam o sujeito no espaço e o obriga a reconstruir novos que possibilitem a reconstituição de sua capacidade de movimento - neste sentido, os bairros, ou 
enclaves, ou guetos étnicos são chave, posto que significam o ponto B de um grande aglomerado de trajetórias acumuladas em relação ao qual o imigrante recém-chegado acabara de deixar o ponto A. Partindo-se desta concepção, o que se nota e que quero enfatizar aqui é justamente a peculiaridade deste ponto de referência boliviano em São Paulo, um ponto que, me arrisco a dizer como disse antes neste ensaio, é menos marcado pelo espaço do que pelo tempo. Em outras palavras, se não há um bairro étnico boliviano a ser (per)seguido - como na música, toda fuga é também uma perseguição -, pode-se falar com mais segurança em um tempo étnico, bairro temporal delimitado pelas fronteiras da costura e cujos produtos residuais, estes sim, serão espaços de aglomeração de multidões de bolivianos, na Kantuta aos domingos e na Coimbra aos sábados - espaços que afinal, mesmo estes, e em especial a Kantuta, chegam a se tornar substantivos incompletos quando mencionados sem o complemento temporal "domingo", que o define.

\section{XII}

Mas com o tempo, essa interseção inicial de trajetórias parece tender a se desfazer. Chalo tomou rumos diferentes dos de Gonzalo e Marta, que tem rumos diferentes de outros bolivianos, e ainda que a grande maioria de uma forma ou de outra, permaneça na costura, creio que isso pode ser afinal um sintoma de liberdade.

Da liberdade falava Román, o artista-xamã boliviano que interpelava seu cliente para tentar falar sobre liberdade à comunidade boliviana como um todo. Mas o que se pode dizer sobre liberdade diante de toda esta história? Juntamente com tantas narrativas de fuga, aparecem também e inevitavelmente narrativas múltiplas de liberdade. A liberdade de Román é a de uma máquina de guerra cosmológica. Román não quer tanto “la isla, ¡Bolivia, Bolivia, Bolivia!”. Román quer a água ao redor da ilha, este oceano paulistano de descobertas que liberta as fronteiras do espírito, mas que também o deixa a mercê de suas intempéries. Para Marta, a máquina libertária é outra. É uma máquina domesticada - tanto quanto doméstica -, e cabe dentro de uma pequena caixa de seres humanos e de fios de costura, onde cabem tanto máquinas de costura quanto máquinas de escape. Já Chalo, por sua vez, fez sua segunda migração já no Brasil, deixando o barro-temporal da costura, quadra a quadra, libertando seu tempo através de horas extras diárias, até chegar à Liberdade. A Liberdade (bairro) levou-o à 
liberdade de um salão de cabeleireiros brasileiro, fuga que se mostrou demasiada para Chalo, que a narra ao fim e ao cabo como frequentemente embaraçosa, de acordo com ele, por não conhecer o idioma. Foi necessário encontrar um meio termo, e Chalo encontrou enfim um salão boliviano para trabalhar e, posteriormente, teve o seu próprio. Fez seu salão na Rua Coimbra em 2002, na época ainda vazia de bolivianos, mas uma vez mais, o movimento de estriamento - pois que o estriamento também pressupõe uma dinâmica de movimento - parece não cessar. Parece se passar algo como um agenciamento gigante de estriamentos. Há que se criar rédeas para o espaço que tanto insiste em fugir de nossas mãos. Através do controle do espaço é que se podem controlar também as memórias. A Kantuta e a Coimbra hoje em dia, com suas pequenas simulações de Bolívia, seja através da comida, da língua, das festas, de quenas ${ }^{5}$ bolivianas e de inúmeros artigos bordados com o símbolo da wiphala ${ }^{6}$, reencenam e estriam a memória coletiva (Halbwachs, 2006), que tão facilmente se deixa perder através de cada quadra a mais que o espírito se arrisca a rodear além daquilo que já conhece. E aí então o que importa é estriar a memória, evitar o nomadismo espiritual criado pelo esquecimento, também máquina de guerra. De acordo com Halbwachs (2006: 170), “é ao espaço, ao nosso espaço - o espaço que ocupamos, por onde passamos muitas vezes, a que sempre temos acesso e que, de qualquer maneira, nossa imaginação ou nosso pensamento a cada instante é capaz de reconstruir - que devemos voltar nossa atenção, é nele que nosso pensamento tem de se fixar para que essa ou aquela categoria de lembranças reapareça". A Rua Coimbra transformou-se bastante desde a chegada de Chalo, quando trabalhava na rua como um boliviano solitário. Chalo narra esta transformação do espaço:

Aí, posteriormente, ya fui conociendo gente, vino un boliviano, un boliviano se avisa a dos, dos bolivianos se avisan a cuatro, ahora es poco a poco, y me estaba volviendo conocido. Aí con el tiempo, me vieran trabajar aquí, y comenzaron a abrir. Aquí abajo había una peluquería que abrió y yo me alegré bastante. 'Ahora ya somos dos'. Y aí se abrió una peluquería más, y ya éramos dos, tres, cuatro. Así sucesivamente. Y bueno... y yo ya no me sentía solo. Me sentía en compañía.

E a Bolívia aos poucos, veio até o Chalo.

\footnotetext{
${ }^{5}$ Quena: flauta tradicional dos Andes feita geralmente de bambu.

6 Wiphala: emblema comumente usado como bandeira, representando os povos nativos dos Andes centrais da Bolívia. Hoje em dia, é tida como segunda bandeira oficial do país.
} 


\section{Referências}

CRUSH, J. Johannesburg, South Africa: breaking with isolation. In: Balbo, M. (ed.) International immigrants and the city. Veneza: UN-HABITAT / Universitá Iuav di Venezia, 2005.

CYMBALISTA, Renato e XAVIER, Iara Rolnik. A comunidade boliviana em São Paulo: definindo padrões de territorialidade. São Paulo: MIUrb-AL, 2007.

DELEUZE, Gilles e GUATTARI, Félix. Mil platôs. Capitalismo e esquizofrenia. Vol. 5. São Paulo: Editora 34, 1997.

HALBWACHS, Maurice. A memória coletiva. São Paulo: Centauro Editora, 2006.

MARCUSE, P. Enclaves sim; guetos não: a segregação e o Estado. In: Revista Espaço e Debates, v.24, n.45, jan-jul. São Paulo: NERU, 2004.

QADEER, M. A. Segregação étnica em uma cidade multicultural, Toronto, Canadá. In: Revista Espaço e Debates, v.24, n.45, jan-jul. São Paulo: NERU, 2004.

VELHO, Gilberto. Subjetividade e sociedade: uma experiência de geração. Rio de Janeiro: Jorge Zahar Editor, 1986.

WACQUANT, Loïc. Três premissas perniciosas no estudo do gueto norte-americano. In: Mana - Estudos de Antropologia Social, v.2, n.2, outubro. Rio de Janeiro: Museu Nacional, 1996.

Recebido em: 15/09/2014 Aprovado em: 22/11/2014 